\title{
Stem Cell Biology in the Lung and Lung Cancers: Using Pulmonary Context and Classic Approaches
}

\author{
D.M. Raiser, S.J. ZachareK, R.R. Roach, S.J. Curtis, K.W. Sinkevicius, \\ D.W. GLUDISH, AND C.F. KIM \\ Stem Cell Program, Children's Hospital Boston, Department of Genetics, Harvard Medical School, \\ and Harvard Stem Cell Institute, Boston, Massachusetts 02115
}

\begin{abstract}
Classic stem cell biology approaches tailored specifically with lung biology in mind are needed to bring the field of lung stem cell biology up to speed with that in other tissues. The infrequent cellular turnover, the diversity of cell types, and the necessity of daily cell function in this organ must be considered in stem cell studies. Previous work has created a base from which to explore transplantation, label retention, and more sophisticated lineage-tracing schemes to identify and characterize stem cell populations in the normal lung. These approaches are also imperative for building on precedents set in other tissues in the exploration of the cancer stem cell hypothesis in lung cancers. Additionally, recent studies provide key leads to further explore the molecular mechanisms that regulate lung homeostasis. Here, we discuss strategies to advance the field of lung stem cell biology with an emphasis on developing new, lung-specific tools.
\end{abstract}

The application of stem cell biology approaches to the lung should reflect the impressively diverse composition of the respiratory epithelium. There are many epithelial cell populations in the lung, each with distinct functions and anatomical locations, that all cooperate to accomplish the vital task of gas exchange (Mason et al. 1997; Rawlins and Hogan 2006). Of particular emphasis for this chapter, the distal murine lung, found beyond the trachea and upper airways, consists of several types of epithelia (Fig. 1). The branching bronchioles and the terminal bronchioles to which they give way are lined with columnar Clara cells that secrete cytokine- and immunoregulatory molecule-rich surfactants and provide a protective barrier in the airways, and ciliated cells that propel secreted surfactant along the bronchiolar wall and function in mucociliary clearance (Massaro et al. 1994; Van der Schans 2007). In the alveolar space, cuboidal alveolar type II (AT2) cells produce the surfactant necessary for the flat alveolar type I (AT1) cells to perform their gasexchange function and deliver oxygen to the blood (Dobbs et al. 1998; Fehrenbach 2001). Clara cells, ciliated cells, AT2 cells, and AT1 cells can be identified by their expression of Clara cell secretory protein (CCSP; also known as Scgb1a1, CCA, CC10, and uteroglobin), acetylated tubulin (Acet Tub), prosurfactant protein C (SPC), and aquaporin 5 (AQ5), respectively (Fig. 2). Notably, murine and human lungs have anatomical differences, such as the relative abundance of each of these cell types along the proximal-distal pulmonary axis (Liu et al. 2006; Rawlins and Hogan 2006).

Several key aspects of lung biology may set the lung apart from other tissues when considering the study of stem cells. First, unlike tissues such as the gut and skin, where the resident epithelium is renewed frequently, murine lung epithelium has little or no turnover in the absence of exogenous stimuli. For comparison, the lining of the small intestine turns over completely every 3-5 days; estimates of lung cell turnover time vary widely (e.g., 6-17 months) and have not been carefully examined in the absence of injury (Rawlins and Hogan 2006). Second, the lung is more similar to the gut and skin than to other epithelial tissues, such as the mammary gland or prostate, in that the pulmonary system is constantly

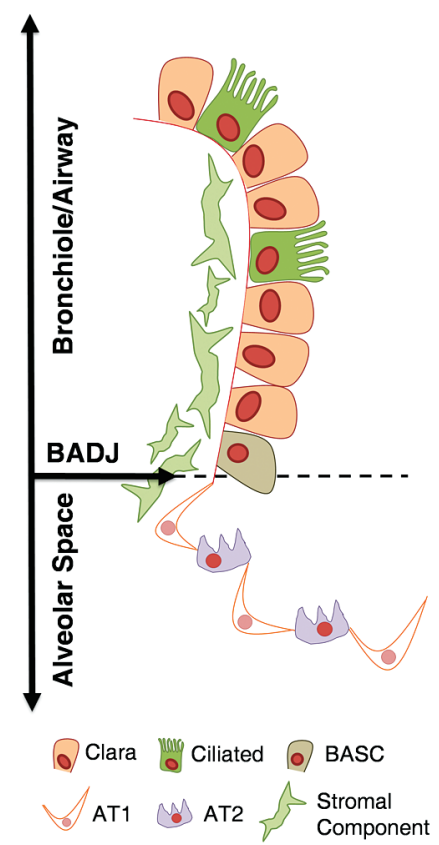

Figure 1. Epithelial organization of the murine distal lung. Clara cells and ciliated cells line the distal airways, with Clara cells being the prominent luminal cell population. The alveolar space is made up of alveolar type I (AT1) and type II (AT2) cells organized in sac-like structures. BASCs (bronchioalveolar stem cells) sit at the junction between the terminal bronchiole and the alveolar space (BADJ, arrow), and stromal components that may include mesenchymal cells and extracellular matrix molecules, underlie epithelia in both regions. 


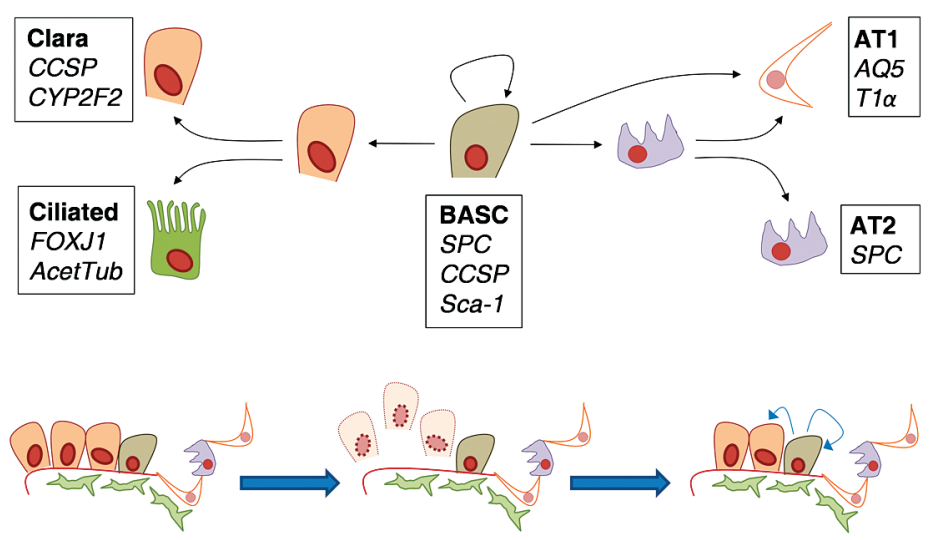

Figure 2. Model of BASC function and distal lung homeostasis. (Top) BASCs serve as stem cells for epithelial cells lining the airways and air space. They are capable of self-renewal (arrow back to BASCs) or differentiating to give rise to Clara, AT1, and AT2 cells in the appropriate physiological settings. In turn, a subset of Clara cells may serve as progenitor cells capable of differentiation to more specialized Clara and ciliated cells (arrows). Similarly, certain AT2 cells may be progenitor cells that give rise to AT2 and AT1 cells (arrows). Boxed near each cell type are markers used to identify each population. (Bottom) Example of proposed BASC function in vivo. BASCs and other lung epithelia are normally quiescent in vivo (left). When Clara cells are ablated by naphthalene (middle), BASCs are stimulated to proliferate, self-renew, and differentiate (arrows) to give rise to Clara cells to repair the damaged epithelium (right).

exposed to potential perturbagens from the outside environment. Together with this risk, the required function of the cells that comprise the lung epithelium for sustained viability makes repair of damage to the lung an urgent matter.

Putting together these unique aspects of lung cell biology, it follows that lung stem cell populations may be a subset of the same cells that function daily as contributors to the gas-exchange machinery, and their stem cell characteristics may only be gleaned in times when injury of more specialized, or more differentiated, cells occurs. An alternative hypothesis is that the majority of cells in the lung may have the potential to give rise to new epithelia, and thus the lung may not contain any stem or progenitor cells, just as has been proposed for the pancreas (Dor and Melton 2004). The concept of "facultative" stem or progenitor cells-defined as cells that differ from "dedicated" stem cells in that they are more differentiated, do not have long-term self-renewal capacity, and do not participate in tissue homeostasis but rather only respond to injury-has also been proposed for the lung and may include either of the models above (Rawlins and Hogan 2006; Stripp and Reynolds 2008). The sections below highlight studies suggesting that the distal lung contains resident stem or progenitor cells and describe the methods that are likely to yield an answer to which of these hypotheses is most correct.

\section{STEM CELLS IDENTIFIED BY COMBINING FLOW CYTOMETRY AND LUNG CELL MARKER EXPRESSION}

The isolation of BASCs added to the understanding of the epithelial diversity of the distal lung (see Fig. 1) (Kim et al. 2005). BASCs were initially identified based on their residence in the region between the bronchiolar and alveolar cells in terminal bronchioles, known as the bron- chioalveolar duct junction (BADJ), and distinct coexpression of CCSP and SPC (Fig. 2). BASCs can be isolated from dissociated murine lung using a fluorescence-activated cell sorting (FACS)-based protocol wherein cells are sorted positively for expression of the cell surface marker Sca-1 and negatively for the endothelial marker CD31 and the hematopoietic marker CD45.

Isolated BASCs have the key stem cell properties of self-renewal and multipotency in that they can be passaged multiple times in culture, and, in clonal assays, they can differentiate into CCSP-positive, SPC-positive, or AQ5-positive cells (singly positive for each) when grown on Matrigel, a basement membrane matrix preparation. Additionally, BASCs are among the first cells to proliferate in vivo in response to naphthalene and bleomycin treatment injury models discussed below.

In addition to their response to lung injury, BASCs are implicated in the onset of lung adenocarcinoma initiated by oncogenic K-ras (Kim et al. 2005; Yang et al. 2008 ) or via other oncogenic aberrations (see below). Significant expansion of the BASC pool occurs following activation of oncogenic K-ras in vivo as well as in a cell-autonomous manner after K-ras is activated in isolated BASCs in culture, and many of the earliest lesions observed in this model arise at the BADJ where BASCs reside. We hypothesize that BASCs are the cell of origin for K-ras-induced lung adenocarcinoma, and we are currently creating the murine alleles needed to test this possibility.

\section{MODELS OF LUNG INJURY IDENTIFIED PUTATIVE LUNG STEM AND PROGENITOR CELLS}

Due to the low turnover rate of the adult lung epithelium, injury models are critical to the process of understanding which lung cell populations are required for 
epithelial regeneration. Stimulation and visualization of lung cell proliferation are facilitated by induction of lung injury; normal mouse lung has few to no epithelial cells that are capable of incorporating nucleotide analogs or staining for Ki-67, indicating that the lung epithelia is largely quiescent (Mason-Richie et al. 2008). Analyses of existing lung injury models, described below, have led to the identification of some putative lung stem cell populations. These models are also useful in formulating hypotheses regarding lung lineage relationships, given that each typically results in the perturbation of only one or a few particular types of epithelial cells.

\section{Naphthalene}

A compound typically found in trace amounts in cigarette smoke and an airborne pollutant, naphthalene causes acute toxicity to Clara cells (Stripp et al. 1995). Mice exposed to naphthalene are depleted of Clara cells, but the bronchiolar epithelium is reconstituted within 2-6 weeks (Van Winkle et al. 1995). A potential stem cell population for the Clara cell lineage_-variant Clara cells - was identified based on their resistance to naphthalene, conferred by lack of expression of a cytochrome P450 enzyme necessary for naphthalene metabolism. Variant Clara cells (so-called because of their CCSP expression) were located in the proximal airways near neuroepithelial bodies and at the BADJ (Reynolds et al. 2000a; Hong et al. 2001; Giangreco et al. 2002). Variant Clara cells residing in the BADJ likely overlap with the BASC population in that they are both naphthalene-resistant and express CCSP. It also remains possible that the BADJ variant Clara cells contain a subset of cells that lack SPC, and therefore, some variant Clara cells may be distinct from BASCs. In short, naphthalene administration serves as one method to analyze BASCs, Clara cells, and the lineages to which they may give rise.

\section{Bleomycin}

Intranasal or intratracheal bleomycin treatment induces alveolar injury characterized by widespread AT1 cell loss, AT2 cell number reduction, and, in some animal strains, a deposition of fibrotic tissue in the pulmonary interstitium with associated inflammation (Adamson 1976; Aso et al. 1976). A return to normal numbers of AT1 and AT2 cells is seen when bleomycin is given at doses low enough to minimize the fibrotic response, and this repair was correlated with bromodeoxyuridine (BrdU) incorporation by AT2 cells (Kawamoto and Fukuda 1990). Homeostatic maintenance and reconstitution of the AT1 cell population have thus been classically attributed to AT2 cells acting as stem or progenitor cells in this setting. In culture, AT2 cells can be induced to exhibit AT1 cell characteristics (Isakson et al. 2001; Bhaskaran et al. 2007), yet our studies showed that AT2 cells lack self-renewal and differentiation ability (Kim et al. 2005); instead, they suggested that BASCs may be responsible for AT1 and AT2 cell maintenance and repair. Bleomycin is thus a tool for AT1, AT2, and BASC lineage analysis.

\section{Cell Ablation Strategies}

Cell ablation via engineered alleles is another classic technique useful to lung cell biology. In CCSP-HSVtk transgenic mice, expression of a herpes simplex virus thymidine kinase controlled by the CCSP promoter (Reynolds et al. 2000b, 2004; Hong et al. 2001) allows selective ablation of CCSP-expressing cells upon administration of the nucleoside analog ganciclovir. In contrast to the naphthalene injury model, CCSP-HSVtk mice are incapable of epithelial repair following ganciclovir treatment, further implicating variant Clara cells and BASCs as necessary regenerative populations following bronchiolar injury. In conjunction with the existing chemical injury models, an inducible means of ablating specific cell populations in the lung - such as the CCSP-HSVtk model or other systems such as doxycycline- and tamoxifeninducibile alleles (e.g., rtTA/tet-O and CreERT ${ }^{2} /$ Lox), which are also useful in lineage tracing (below) (Tichelaar et al. 2000; Rawlins et al. 2007) —will be invaluable in pinpointing the cell types that are necessary for lung repair in various contexts.

\section{Partial Pneumonectomy}

The murine lung undergoes regeneration after surgical removal of one or several lobes, referred to as partial pneumonectomy. This response is a compensatory overgrowth of the remaining lung attributed to cellular proliferation, yet the contribution of lung stem cells to this response is unknown. Using in vivo analyses after pneumonectomy and comparison of observed data to a mathematical model, we determined that both BASCs and AT2 cells are likely to be important in lung regrowth (NolenWalston et al. 2008). BASCs elicited the earliest and most significant proliferative response to partial pneumonectomy, before restoration of lung function capacity. Modeling data supported the hypothesis that BASCs may contribute to alveolar regeneration and showed that AT2 cells likely function as the cell type with the greater expansion potential to increase alveolar surface area; these studies support and contribute to our model of BASC function (below and Fig. 2). This work is the first demonstration of integrating approaches including physiology and systems biology to understand the adult lung and lung stem cell biology; such combined methodology is likely to be important in understanding the direct clinical implications of murine lung stem cell advances.

Although these and other injury models were crucial in the process of laying the groundwork for lung stem cell biology, it is of note that these models may have some limitations in precisely recapitulating how the lung is maintained and injured during aging or when lung injuries from exogenous agents, such as smoking, pollutants, and cold or flu viruses, are encountered. Most environmental insults faced by the lung epithelia contain many chemical components that likely impact many cell types at once: Cigarette smoke is likely to damage multiple cell types simultaneously. Therefore, chemicals that ablate only one cell type may not represent the entire potential of stem or progenitor cells when used for performing lineage tracing. 


\section{A STEM CELL MODEL FOR DISTAL LUNG HOMEOSTASIS}

The in vivo lung injury and ex vivo culture experiments described above, together with new insights from the analysis of molecules that likely function in BASC control (see below), have led us to develop a working model for the function of BASCs and other distal lung epithelia in lung homeostasis (Fig. 2) (Kim et al. 2005; Kim 2007b). First, we hypothesize that BASCs sit atop a hierarchy of epithelial cells lining the airways and air space, aptly and uniquely positioned to contribute to epithelial repair in both compartments (Figs. 1 and 2). Thus, BASCs are capable of giving rise to Clara, AT1, and AT2 cells in the context of particular physiological settings. Subsets of Clara cells may serve as progenitor cells with the capacity to produce more differentiated Clara cells (e.g., variant Clara cells may be progenitors for more specialized Clara cells), as has been proposed by Stripp and colleagues (Hong et al. 2001), and Clara cells may also be progenitors for ciliated cells (Asmundsson et al. 1973; Evans et al. 1986; Rawlins et al. 2007; Reynolds et al. 2008). Similarly, AT2 cells may be progenitors that replenish subsets of specialized AT2 cells as well as AT1 cells. As depicted in Figure 2, there are no known molecular markers to functionally separate Clara cell or AT2 cell subsets in vivo. In this model, BASCs may be most similar to the multipotent hematopoietic stem cell, whereas Clara and AT2 cell subsets may be akin to lymphoid or myeloid progenitors, and specialized Clara cells and AT1 cells may be the terminally differentiated cells, as are $\mathrm{T}$ cells and red blood cells (Metcalf 2007). Importantly, in this model, evidence that Clara cells contribute to new Clara cells (e.g., via lineage tracing) would not rule out the potential contribution of BASCs to Clara cell lineages in particular physiological settings. Furthermore, a lack of BASC contribution to particular lineages in some experiments (e.g., to alveolar cells in lung development) does not exclude their ability to yield various lineage progeny in the right setting (e.g., to alveolar cells if both bronchiolar and alveolar cells are injured or absent).

Just as our model does not rule out the possibility of stem or progenitor cell activity in cell types other than BASCs, this hypothesis also does not require that BASCs contribute to developing or aging lung. In several independent studies, the BASC population does not become apparent - at least, as defined by SPC and CCSP coexpression-until after birth (Tyagi et al. 2007; Reynolds et al. 2008; Zhang et al. 2008; C. Kim, unpubl.). Thus, BASCs are likely not required for embryonic development of the lung. Wuenschell et al. (1996) reported that embryonic lung cells simultaneously exhibit staining for Clara, AT2, and neuroendocrine cell markers, whereas Whitsett and others have suggested that these cell types have distinct points of derivation (Perl et al. 2002). Because BASCs can differentiate into alveolar cells in culture and a significant percentage of alveoli are formed after birth, it remains possible that BASCs have a role in postnatal alveolar expansion and development; the developmental origins of BASCs remain to be defined.

\section{LINEAGE TRACING IN THE LUNG}

Lineage-tracing techniques (Stern and Fraser 2001; Barker et al. 2007) represent one approach needed to test models for lung homeostasis. To date, genetic lineage tracing of bronchiolar and alveolar cell types has been complicated by the expression of lineage markers in the embryonic lung epithelium and misexpression of transgenes driven by lung cell-type promoters (Whitsett and Perl 2006). To use lineage tracing in any tissue, it is necessary to have suitable markers that are exclusively expressed in the population of interest. This has been possible for analysis of the potential ciliated cell contribution to Clara cells using a tamoxifen-inducible ciliated cell-specific recombinase allele combined with a recombinase reporter allele (Rawlins et al. 2007). Because we have not yet identified a gene that is exclusively expressed in the BASC population for use in this manner, we are using genetic strategies that take advantage of our current knowledge of BASC markers, their known intersection or exclusion with regard to expression in other cell types, and multiple recombinase and reporter allele systems. We predict that as the more precise genetic tools we and others (see, e.g., Rawlins et al., this volume) are building become available, lung biology and lung stem cell biology will grow in its level of specificity and, more importantly, increase the knowledge of this complex organ.

Results from lineage tracing in the lung must be interpreted keeping in mind the biology of this tissue. A positive result in this scenario is sound evidence for lineage potential, but due to potential inconsistencies in recombination efficiency and injury efficacy, a negative result does not necessarily indicate that the cell population intended for marking is not a stem cell population. In addition, especially in the absence of injury in this relatively quiescent tissue, counting the percentage of labeled lung cells in a given pulse-chase experiment (e.g., tamoxifen to activate Cre recombinase, the pulse, followed by a waiting time for Cre reporter readout, the chase) is not necessarily related to self-renewal or differentiation without coincident evidence of cellular proliferation over the analyzed chase time.

\section{LABEL RETENTION AS A LINEAGE TRACER}

Traditionally, the definition of an adult stem cell has included the quiescent descriptor, indicating that the true stem cell divides infrequently. It follows that label retention can be used as a marker of stem cells when performing pulse-chase experiments. Indeed, many have used this technique successfully for this purpose (Potten et al. 1992; Tumbar et al. 2004), and yet, recent findings suggest that label retention does not necessarily identify the tissue stem cell (Barker et al. 2007; Kiel et al. 2007). It is equally important to note that the extent of stem cell quiescence is likely to vary from tissue to tissue. Thus, both label-retention and marker-based fate mapping can be useful in identifying stem cell populations, and the best approach may be a combinatorial one.

To test the utility of label retention in lung stem cell isolation, we are using a doxycycline-inducible H2B-green 
fluorescent protein (GFP) system in which chromatinbound GFP can be expressed in a temporal fashion and lost over time with cell division (Kanda et al. 1998; Tumbar et al. 2004). We have determined that we can use this H2B-GFP allele with the reverse tetracycline activator driven by Rosa26 to label lung epithelia in vivo with temporal control (Fig. 3). With this approach, we will be able to analyze cell turnover in normal lung and in response to lung injury without the bias of known markers. Isolation and molecular characterization of GFP-pos- itive lung cells with stem cell function could then lead to new markers for putative stem cells.

\section{TRANSPLANTATION OF LUNG STEM CELLS}

Upon isolation of putative adult stem cell populations, demonstration of their ability to effectively contribute to tissue-specific cell types and, in some cases, to repairing damaged or diseased tissue in a transplantation assay has proven to be compelling evidence for bona fide stem cell
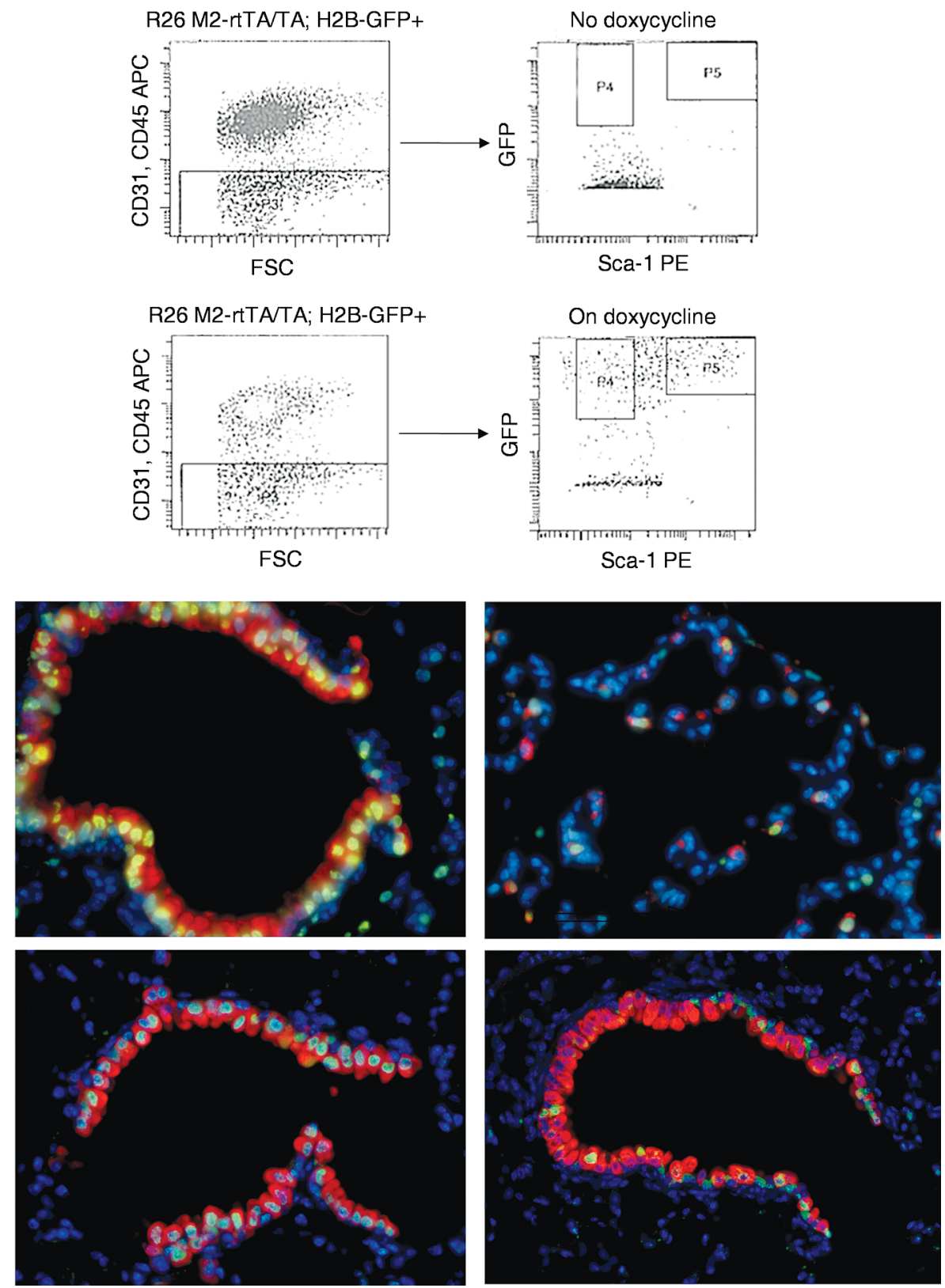

Figure 3. Inducible H2B-GFP expression in lung epithelial cells. FACS analysis shows that GFP expression in CD31- and CD45-negative lung cells, including BASCs (P5) and other epithelial cells (P4) from Rosa26-M2rtTA; H2B-GFP is absent in mice that did not receive doxycycline (top graph), whereas GFP is present in mice that received doxycycline treatment (bottom graph). In lung tissue sections, terminal bronchiole (TB) (top left) and alveolar space (top right) after a 1-week pulse of doxycycline, and no chase period, showed GFP labeling of Clara cells and AT2 cells, respectively. (Bottom, left and right) TB 1 month after doxycycline pulse and mocktreated (bottom left) or naphthalene-treated (bottom right) mouse, showing loss of GFP label after repair. (Red) CCSP (top left, bottom left and right) or SPC (top right); (green) GFP; (blue) DAPI. 
function (Till and McCullough 1961). Tissues in which this contribution has been observed include the brain, retina, skin, and muscle (Meissner et al. 2005; MacLaren et al. 2006; Mavilio et al. 2006; Cerletti et al. 2008). In some tissues, such as the blood and the mammary gland, it has even been possible to observe complete reconstitution of mature, fully differentiated tissues from the orthotopic transplantation of a single stem cell (Osawa et al. 1996; Shackelton et al. 2006). For other tissue-specific stem cells, subcutaneous injection of stem cells with supporting mesenchymal cells allowed the formation of structures that resemble the tissue of interest (Blanpain et al. 2004; Richardson et al. 2004; Lawson et al. 2007). The lung lags behind these tissues in the development of an orthotopic transplantation assay, due in no small part to the complex architecture of the lung and the unique air-epithelium interface that exists in the pulmonary lumen.

We are developing a transplantation protocol to assess the ability of putative lung stem cells to contribute to lung epithelial lineages. By using the injury models discussed above, we will be able to examine the contribution of transplanted stem cells in various contexts, both when the endogenous stem cell niche is intact and when the endogenous niche is cleared. We are also investigating the potential of purified adult lung cell populations to function in environments that support lung development. One such current approach is to inject normal putative lung stem cell populations from the mouse into the prelung mesenchymal field in the developing chicken embryo, similar to the example of how the developing chicken nervous system was used to test the potential of adult rat neural crest stem cells (Mosher et al. 2007). These studies may reveal a robust assay for lung stem cell self-renewal and differentiation potential in vivo. In combination with other genetic tools currently under development, transplantation studies will contribute to our understanding of the biological pool of cells with the potential to maintain lung epithelial tissue in vivo.

\section{EXTENDING THE LUNG STEM CELL QUESTION TO CANCER}

The cancer stem cell (CSC) hypothesis, which suggests that tumors are maintained by a population of cells possessing stem cell characteristics, has emerged as an attractive explanation for tumor growth, recurrence, and metastasis (Reya et al. 2001). Methods used in identification and characterization of stem cell populations from normal adult tissues have proven to be useful in uncovering cancer stem cell populations, yet this important concept in stem cell biology has not yet been carefully explored in the lung.

The results of multiple studies suggest that murine lung adenocarcinoma contains a CSC population. In a mouse model of lung adenocarcinoma initiated with oncogenic Kras, the BASC population expands early and specifically after K-ras activation, and BASC-like cells can be found in the developed tumors (Jackson et al. 2001; Kim et al. 2005). Similar results have been reported in additional genetic models of lung adenocarcinoma, strongly implicating BASCs in tumor initiation and progression (Besson et al.
2007; Pei et al. 2007; Ventura et al. 2007; Yanagi et al. 2007; Yang et al. 2008). Development of a lung cancer cell transplantation assay has yielded further evidence suggesting the presence of a CSC population in murine lung adenocarcinoma, and studies to rigorously test the tumor-propagating potential of subpopulations of murine lung adenocarcinoma cells, including BASC-like cells, in this assay are under way in our lab (S. Curtis et al., unpubl.).

Several pieces of evidence suggest that human lung cancers also contain a population of cells with stem cell characteristics. First, the majority of newly diagnosed lung cancer patients have tumors that are already metastatic or refractory to chemotherapeutics or that quickly become resistant to chemotherapeutics. For example, the initial sensitivity of human adenocarcinomas with activating epidermal growth factor receptor (EGFR) mutations to EGFR tyrosine kinase inhibitors and the acquired resistance to these treatments suggest that drug-resistant CSCs may be present in these tumors (Kobayashi et al. 2005; Pao et al. 2005; Kosaka et al. 2006). Second, side population cells, isolated by their ability to efflux Hoechst dye, were identified in six human lung cancer cell lines; these cells exhibit increased drugexporting transporter expression, enriched tumor-propagating capacity, and resistance to multiple chemotherapies (Ho et al. 2007). Third, CD133 ${ }^{+}$cells from human lung tumors (and not $\mathrm{CD} 133^{-}$cells) were recently shown to form self-renewing spheres in culture that could propagate tumors when transplanted subcutaneously into immunodeficient mice (Eramo et al. 2008). Importantly, although these studies support the likelihood of CSCs in lung cancers, the isolation and characterization of a population of human lung cancer cells that can serially propagate the lung tumor phenotype in the lung microenvironment have not been reported.

The most widely used technique for identification of CSCs uses a combination of cell surface markers that select cells with expression patterns similar to those of more primitive cells and distinct from those of differentiated cell lineages, followed by transplantation of sorted cancer cells into immunodeficient mice. CSCs in human leukemia, breast, brain, colon, pancreatic, and melanoma malignancies have been shown to be required for serial rounds of tumor propagation in transplantation assays that often use orthotopic strategies (Bonnet and Dick 1997; Al-Hajj et al. 2003; Singh et al. 2004; Dalerba et al. 2007; Li et al. 2007; O'Brien et al. 2007; Ricci-Vitiani et al. 2007; Schatton et al. 2008). Subcutaneous injections are commonly used to test tumor-propagating activity due to the ease of accessing the injection site and monitoring tumor progression, and the highly vascular environment under the kidney capsule that promotes cancer cell engraftment and proliferation is also used (Xin et al. 2005). However, such assays do not reflect the normal cellular milieu in which tumors arise, grow, and progress. Importantly, transplanting tumor cells into the normal microenvironment may most accurately reflect cancer progression, niche effects on CSCs, and cancer cell response to therapeutics (Li and Neaves 2006; Scadden 2006). Particularly important for future work to develop therapeutic intervention of lung CSCs, previous studies 
have shown that lung tumor cells growing in subcutaneous regions do not exhibit the same physiological response to chemotherapy as do tumors growing in the lung (Onn et al. 2003; Fujino et al. 2005). Therefore, injection of murine or human lung cancer cells into the lungs of recipient mice will be crucial in future studies to monitor CSCs in the lung microenvironment (McLemore et al. 1987).

\section{ADDITIONAL MARKERS ARE NEEDED TO STUDY LUNG CANCER STEM CELLS}

We have determined that markers of murine BASCs allow prospective identification of cancer stem cells from murine lung tumors in some settings (above), yet it will be crucial to find additional markers to isolate human lung CSCs. One key BASC marker, Sca-1, is not expressed on human cells, and a second positive BASC marker, CD34, has been shown to be present on other cell types found in human lung tissue (Gomperts and Strieter 2007). In addition, in our own recent studies, we found that the current commercially available antibodies for CD34 may overestimate BASC numbers and should be used with caution (R. Roach and C. Kim, unpubl.). For lung CSC studies, it may be useful to test markers that have been used to isolate CSCs from other types of primary solid human tumors. For example, human lung tumors could be sorted for CD133, which is expressed on brain, colon, and putative lung CSCs (Singh et al. 2004; O'Brien et al. 2007; Ricci-Vitiani et al. 2007; Eramo et al. 2008), and epithelial cell adhesion molecule (EpCAM), which is expressed on breast, pancreatic, and colon CSCs (Al-Hajj et al. 2003; Dalerba et al. 2007; Li et al. 2007), for use in serial transplantation experiments.

It will likely be important to also use bioinformatic and genetic approaches to identify murine and human lung CSCs. Bioinformatic analyses, which evaluate the differences between human normal lung and lung adenocarcinoma gene expression profiles, may reveal cell surface markers that correlate with tumor-propagation ability, because the number of CSCs is likely to be higher in lung tumors compared to normal tissues (Bhattacharjee et al. 2001; Beer et al. 2002; Garber et al. 2002; Powell et al. 2003). Direct comparison of normal stem cells to other lung cell types may also be valuable. For example, comparing gene expression data of BASCs versus other epithelial cells in normal and tumorigenic lungs may lead to the identification of novel lung CSC markers. In addition, culture-based assays may be useful surrogates for the identification of CSC markers. In parallel with studies to identify novel murine and human lung cancer cell or BASC surface markers, it is also critical to determine if the normal human lung has population(s) with stem cell functions.

\section{GENETIC APPROACHES FOR CANCER STEM CELLS}

Just as for testing models of lung homeostasis, the use of genetic strategies to identify lung CSCs will also be advantageous. One such approach would use cell-type- specific ablation to test the function of defined subsets of cancer cells in situ. Targeted ablation of putative cancer stem cells would further determine the necessity of that same cell population in the context of an endogenous tumor and thus directly interrogate the role of such cells in tumor maintenance. Targeted cell ablation can be achieved using lineage-restricted expression of suicide genes such as the diphtheria toxin A (DTA) chain or the herpes simplex virus-1 thymidine kinase (HSVtk) (above) (Breitman et al. 1987; Palmiter et al. 1987; Borrelli et al. 1988). Such strategies have been used in a variety of settings to understand the roles of cell populations in the context of development and niche effects (Lee et al. 2000; Visnjic et al. 2004; Ito et al. 2005; Sangiorgi and Capecchi 2008), and we anticipate a similar utility for this strategy in the study of lung cancer stem cell biology.

\section{PATHWAYS IMPLICATED IN BASC FUNCTION}

Just as the precise cellular mechanisms of lung homeostasis and lung cancer maintenance are poorly understood, the pathways that regulate lung stem cells are largely unknown. Several recent publications have described the identification of players that may be key in lung stem cell function, and assays more focused on particular lung cell subsets and stem cell activities are likely to lead to even more insight into lung homeostasis. Importantly, the factors that regulate features of stem cells, such as quiescence, self-renewal, and differentiation, may be distinct in the lung compared to other types of adult stem cells, given the unique attributes of lung biology discussed above. In addition, pathway abrogation can impact only one or several of the functions of lung stem cells, as seen in recent studies described below.

Regulation of stem cell quiescence, renewal, or terminal differentiation is ultimately dependent on modulating the cell cycle and cell growth machinery (Orford and Scadden 2008), and several components of the cell cycle regulation machinery have been implicated in BASC function. Deficiency of p18Ink4c, but not p27CIP/KIP, two different negative regulators of the $\mathrm{Rb}$ pathway, led to increased BASC numbers and a greater incidence of lung tumor development in corresponding knockout mice. Lungs of $\mathrm{p} 18^{-/-} ; \mathrm{Men}^{+/-}$mice were more densely populated with BASCs, and these mice developed adenocarcinomas as well as neuroendocrine carcinomas. This finding raises the intriguing possibility that BASCs have the potential to contribute not only to adenocarcinomas, but also to tumors that are hypothesized to derive from neuroendocrine cells (Meuwissen and Berns 2005). Interestingly, although the tumor suppressor function of p27 is not required in BASC regulation (Pei et al. 2007), an alternative oncogenic function of p27 may be involved (Besson et al. 2007; Kossatz and Malek 2007; Sicinski et al. 2007). BASC numbers were elevated in mice bearing a p27 mutant allele that is incapable of binding and inhibiting cyclins/CDKs. The $p 27 C K^{-}$allele also acted in a dominant fashion to promote tumorigenesis in multiple organs, including the lung (Besson et al. 2007). Because signaling directed by mitogen-activated protein kinase 
kinase (MAP2K) or Ras and AKT may promote the cytoplasmic localization of this form of $\mathrm{p} 27$ (Chu et al. 2008), these effectors may contribute to BASC dysfunction in cancer.

Although oncogenic K-ras signaling was the first described driver of BASC expansion in tumorigenesis (Kim et al. 2005), the downstream effectors and pathways collaborating with K-ras in promoting this stem cell activity have been unknown. However, several recent publications now demonstrate the potential contribution of the phosphoinositol-3 kinase (PI3K)/PTEN pathway in BASC function and lung tumorigenesis (Yanagi et al. 2007; Dave et al. 2008; Iwanaga et al. 2008; Yang et al. 2008). Each study took a slightly different approach to conditionally inactivate PTEN within the lung, with varying outcomes; in some scenarios, PTEN disruption during postnatal stages led to BASC expansion, impaired differentiation into alveolar lineages, and increased lung adenocarcinoma development, whereas lung tumorigenesis did not occur in other studies of PTEN deficiency in the lung. Interestingly, elevated levels of activated AKT, Bcl2, c-Myc, and Shh were detected in PTEN-disrupted lungs (Yanagi et al. 2007). BASC expansion in activated $\mathrm{K}$-ras-induced tumors was diminished by inhibition of PI3K by the specific inhibitor PX-866 (Ihle et al. 2004). Given that PI3K is a master regulator of multiple growth signaling networks, it will be important to determine the specific downstream effectors important in this activity in the lung. Recent studies indicate that the kinase LKB1, a negative regulator of the PI3K/TOR (target of rapamycin) pathway, is frequently mutated in lung cancers, and its disruption is the most potent genetic event collaborating with oncogenic K-ras induction in lung tumorigenesis ( Ji et al. 2007); whether mutation of LKB1 affects BASC activity is unknown.

Several other recent reports explored the role of lung developmental regulators on BASC function (Ventura et al. 2007; Reynolds et al. 2008; Zhang et al. 2008). The $\mathrm{Wnt} / \beta$-catenin pathway is active in early lung development and declines upon terminal differentiation (Reynolds et al. 2008). Upon conditional expression of an activated form of $\beta$-catenin in the developing lung, differentiation of Clara cells was inhibited and an expansion of cells with BASC markers was observed (Reynolds et al. 2008; Zhang et al. 2008). When Gata6, a transcription factor known to be important in lung epithelial development (Yang et al. 2002), was conditionally depleted, severe differentiation defects resulted, coinciding with the premature detection of BASCs in embryonic lungs.

The Wnt receptor Fzd2 was determined to be an essential downstream effector of Gata6 function, indicating the potential importance of both canonical and noncanonical Wnt signaling in BASC function. MAPK14 (also known as $\mathrm{p} 38 \alpha$ ) has recently been implicated in acting downstream from Wnt5a and Fzd2 to suppress the Wnt/ $\beta$ catenin noncanonical signaling pathway (Ma and Wang 2007), and the conditional knockout of MAPK14 in the postnatal lung also caused BASC expansion, disrupted epithelial differentiation, and collaborated with oncogenic K-ras to enhance lung tumorigenesis (Ventura et al. 2007). MAPK14 had been previously linked to affecting proliferation and differentiation through inhibition of EGFR and activation of $\mathrm{c} / \mathrm{EBP} \alpha$, respectively, and were implicated in BASC function in these studies.

Our recent studies of Bmil deficiency within the lung indicate a spectrum of requirements for this Polycomb group protein in BASC function and lung cancer initiation and progression (Dovey et al. 2008), just as hematopoietic cells and neural cells may rely on Bmil for similar functions (Pietersen and van Lohuizen 2008). Although lung development occurs normally in Bmil null mice (van der Lugt et al. 1994), BASCs isolated from these mice are incapable of self-renewal in culture. Bmi1 null BASCs are capable of differentiation on matrigel, although preliminary studies indicate that they may differentiate more readily relative to wild-type BASCs (S. Zacharek and C. Kim, unpubl.). In response to lung injury, Bmi1 null mice show a reduced expansion of BASCs and inhibited ability to effect repair of the damaged epithelium (Fig. 4). The deficiencies observed in Bmil null BASCs in normal and injured lungs are mirrored in the oncogenic setting of $\mathrm{K}$-ras activation: Lung tumorigenesis and BASC expansion initiated by oncogenic K-ras were inhibited by loss of Bmi1. Although the spontaneous activation of K-rasG12D from the K-rasLA2 allele normally results in rapid tumor progression and adenoma development within 9 weeks (Johnson et al. 2001), Bmil deficiency halted this progression at the earliest hyperplastic stage. The defects

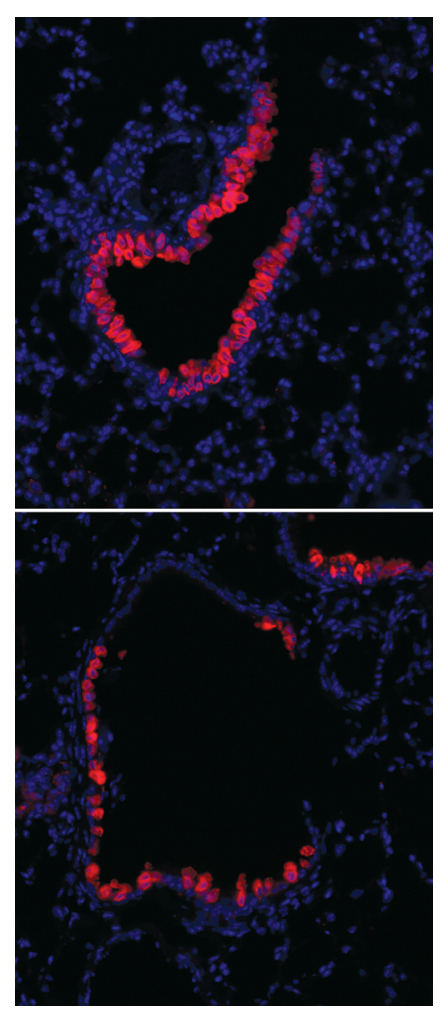

Figure 4. Bmil mutants are impaired in restoring the bronchiolar epithelium following naphthalene-induced lung injury. Lungs of Bmil mutant (bottom) or wild-type mice (top) were stained for CCSP (red) and the nuclear marker DAPI (blue) 1 month after naphthalene damage. Note the reduced incidence of Clara cells in the mutant. 
exhibited by Bmil null BASCs in culture and in response to K-ras activation are partially due to up-regulated p19Arf function, although other effectors are clearly involved. Determining such additional Bmil target genes may point to other key pathways essential to BASC function.

Importantly, in the majority of the studies described above, the effects of these genetic abrogations on stemcell-specific functions, such as self-renewal and differentiation on isolated cells, were not examined (Kim 2007a). This, coupled with the fact that the recombinase strains used in the studies discussed above were not BASC-specific, leave open the possibility that these pathways are not critical solely in BASCs, but are also crucial in other lung epithelial or stromal cells. Assessment of stem cell self-renewal, proliferation, and differentiation should be a minimum requirement in concluding that a gene regulates any adult stem cell population, including the lung. In addition, the development of new genetic tools, such as BASC-specific Cre lines coupled with conditional alleles of genes now suggested to promote (K-ras, p27CK, Bmil, PI3K, Wnt, $\beta$-catenin) or restrain (p18, PTEN, MAPK14, GATA6) BASC function, will allow a more detailed evaluation of the cell-autonomous effects of these genetic alterations on BASC function.

\section{CONCLUSIONS}

Tools for studying stem cells and cancer biology that have proven their value in other tissues will have great utility in the elucidation of stem cell function in the lung, once we add a pulmonary-specific mindset to their use and interpretation. The most insightful work in this field is likely to come from combining the concepts described here: Chemical lung injury models should be combined with lineage-tracing techniques, cell sorting using molecular markers can be used with transplantation schemes, genetics should be applied to the study of cancer stem cells in endogenous tissues, and molecular screens should be performed with clonal assays for self-renewal and differentiation. With so many questions to answer, there is plenty of room for innovation to address the important question of how stem cell biology can be used to understand lung function and lung disease.

\section{ACKNOWLEDGMENTS}

We thank Jen Shepard Dovey, Jackie Lees, Andrew Hoffman, Rose Nolen-Walston, and all of our other collaborators for their efforts that contributed to the completed and ongoing studies described here. We also thank Sandra Ryeom for a critical reading of the manuscript. Our studies are supported by the Harvard Stem Cell Institute Seed Grant and Stem Cell Regulation Junior Faculty Program, RO1 HL090136, the Dana Farber Harvard Cancer Center Career Development Award, an American Cancer Society Research Scholar grant, the March of Dimes Basil O'Conner Award, the V Foundation for Cancer Research, the Joan Scarangello Lung Cancer Foundation, and the Children's Hospital Boston Stem Cell Program.

\section{REFERENCES}

Adamson, I.Y. 1976. Pulmonary toxicity of bleomycin. Environ. Health Perspect. 16: 119-125.

Al-Hajj, M., Wicha, M.S., Bentio-Hernandez, A., Morrison, S.J., and Clarke M.F. 2003. Prospective identification of tumorigenic breast cancer cells. Proc. Natl. Acad. Sci. 100: 39833988.

Asmundsson, T., Kilburn, K.H., and McKenzie, W.N. 1973. Injury and metaplasia of airway cells due to SO2. Lab. Invest. 29: 41-53.

Aso, Y., Yoneda, K., and Kikkawa, Y. 1976. Morphologic and biochemical study of pulmonary changes induced by bleomycin in mice. Lab. Invest. 35: 558-568.

Barker, N., van Es, J.H., Kuipers, J., Kujala, P., van den Born, M., Cozijnsen, M., Haegebarth, A., Korving, J., Begthel, H., Peters, P.J., and Clevers, H. 2007. Identification of stem cells in small intestine and colon by marker gene Lgr5. Nature 449: 1003-1007.

Beer, D.G., Kardia, S.L., Huang, C.C., Giordano, T.J., Levin, A.M., Misek, D.E., Lin, L., Chen, G., Gharib, T.G., Thomas, D.G., et al. 2002. Gene-expression profiles predict survival of patients with lung adenocarcinoma. Nat. Med. 8: 816-824.

Besson, A., Hwang, H.C., Cicero, S., Donovan, S.L., GurianWest, M., Johnson, D., Clurman, B.E., Dyer, M.A., and Roberts, J.M. 2007. Discovery of an oncogenic activity in p $27^{\text {Kip } 1}$ that causes stem cell expansion and a multiple tumor phenotype. Genes Dev. 21: 1731-1746.

Bhaskaran, M., Kolliputi, N., Wang, Y., Gou, D., Chintagari, N.R., and Liu, L. 2007. Trans-differentiation of alveolar epithelial type II cells to type I cells involves autocrine signaling by transforming growth factor $\beta 1$ through the Smad pathway. J. Biol. Chem. 282: 3968-3976.

Bhattacharjee, A., Richards, W.G., Staunton, J., Li, C., Monti, S., Vasa, P., Ladd, C., Beheshti, J., Bueno, R., Gillette, M., et al. 2001. Classification of human lung carcinomas by mRNA expression profiling distinct adenocarcinoma subclasses. Proc. Natl. Acad. Sci. 98: 13790-13795.

Blanpain, C., Lowry, W.E., Geoghegan, A., Polak, L., and Fuchs, E. 2004. Self-renewal, multipotency, and the existence of two cell populations within an epithelial stem cell niche. Cell 118: 635-648.

Bonnet, D. and Dick J.E. 1997. Human acute myeloid leukemia is organized as a hierarchy that originates from a primitive hematopoietic cell. Nat. Med. 3: 730-737.

Borrelli, E., Heyman, R., Hsi, M., and Evans, R.M. 1988. Targeting of an inducible toxic phenotype in animal cells. Proc. Natl. Acad. Sci. 85: 7572-7576.

Breitman, M.L., Clapoff, S., Rossant, J., Tsui, L.C., Glode, L.M., Maxwell, I.H., and Bernstein, A. 1987. Genetic ablation: Targeted expression of a toxin gene causes microphthalmia in transgenic mice. Science 238: 1563-1565.

Cerletti, M., Jurga, S., Witczak, C.A., Hirshman, M.F., Shadrach, J.L., Goodyear, L.J., and Wagers, A.J. 2008. Highly efficient, functional engraftment of skeletal muscle stem cells in dystrophic muscles. Cell 134: 37-47.

Chu, I.M., Hengst, L., and Slingerland, J.M. 2008. The Cdk inhibitor p27 in human cancer: Prognostic potential and relevance to anticancer therapy. Nat. Rev. Cancer. 8: 253-267.

Dalerba, P., Dylla, S.J., Park, I.K., Liu, R., Wang, X., Cho, R.W., Hoey, T., Gurney, A., Huang, E.H., Simeone, D.M., et al. 2007. Phenotypic characterization of human colorectal cancer stem cells. Proc. Natl. Acad. Sci. 104: 10158-10163.

Dave, V., Wert, S.E., Tanner, T., Thitoff, A.R., Loudy, D.E., and Whitsett, J.A. 2008. Conditional deletion of Pten causes bronchiolar hyperplasia. Am. J. Respir. Cell Mol. Biol. 38: 337345.

Dobbs, L.G., Gonzalez, R., Matthay, M.A., Carter, E.P., Allen, L., and Verkman, A.S. 1998. Highly water-permeable type I alveolar epithelial cells confer high water permeability between the airspace and vasculature in rat lung. Proc. Natl. Acad. Sci. 95: 2991-2996.

Dor, Y. and Melton, D.A. 2004. How important are adult stem cells for tissue maintenance? Cell Cycle 3: 1104-1106.

Dovey, J.S., Zacharek, S.J., Kim, C.F., and Lees, J.A. 2008. 
Bmil is critical for lung tumorigenesis and bronchioalveolar stem cell expansion. Proc. Natl. Acad. Sci. 105: $11857-$ 11862.

Eramo, A., Lotti, F., Sette, G., Pilozzi, E., Biffoni, M., Di Virgilio, A., Conticello, C., Ruco, L., Peschle, C., and De Maria, R. 2008. Identification and expansion of the tumorigenic lung cancer stem cell population. Cell Death Differ. 15: 504-514.

Evans, M.J., Shami, S.G., Cabral-Anderson, L.J., and Dekker, N.P. 1986. Role of nonciliated cells in renewal of the bronchial epithelium of rats exposed to NO2. Am. J. Pathol. 123: $126-133$.

Fehrenbach, H. 2001. Alveolar epithelial type II cell: Defender of the alveolus revisited. Respir. Res. 2: 33-46.

Fujino, H., Kondo, K., Ishikura, H., Maki, H., Kinoshita, H., Miyoshi, T., Takahashi, Y., Sawada, N., Takizawa, H., Nagao, T., Sakiyama, S., and Monden, Y. 2005. Matrix metalloproteinase inhibitor MMI-166 inhibits lymphogenous metastasis in an orthotopically implanted model of lung cancer. Mol. Cancer Ther. 4: 1409-1416.

Garber, M.E., Troyanskaya, O.G., Schluens, K., Petersen, S., Thaesler, Z., Pacyna-Gengelbach, M., van de Rijn, M., Rosen, G.D., Perou, C.M., Whyte, R.I., et al. 2002. Diversity of gene expression in adenocarcninoma of the lung. Proc. Natl. Acad. Sci. 98: 13784-13789.

Giangreco, A., Reynolds, S.D., and Stripp, B.R. 2002. Terminal bronchioles harbor a unique airway stem cell population that localizes to the bronchoalveolar duct junction. Am. J. Pathol. 161: 173-182.

Gomperts, B.N. and Strieter, R.M. 2007. Fibrocytes in lung disease. J. Leukoc. Biol. 82: 449-456.

Ho, M.M., Ng, A.V., Lam, S., and Hung, J.Y. 2007. Side population in human lung cancer cell lines and tumors is enriched with stem-like cancer cells. Cancer Res. 67: 4827-4833.

Hong, K.U., Reynolds, S.D., Giangreco, A., Hurley, C.M., and Stripp, B.R. 2001. Clara cell secretory protein-expressing cells of the airway neuroepithelial body microenvironment include a label-retaining subset and are critical for epithelial renewal after progenitor cell depletion. Am. J. Respir. Cell Mol. Biol. 24: 671-681.

Ihle, N.T., Williams, R., Chow, S., Chew, W., Berggren, M.I., Paine-Murrieta, G., Minion, D.J., Halter, R.J., Wipf, P., Abraham, R., Kirkpatrick, L., and Powis, G. 2004. Molecular pharmacology and antitumor activity of PX-866, a novel inhibitor of phosphoinositide-3-kinase signaling. Mol. Cancer Ther. 3: 763-772.

Isakson, B.E., Lubman, R.L., Seedorf, G.J., and Boitano, S. 2001. Modulation of pulmonary alveolar type II cell phenotype and communication by extracellular matrix and KGF. Am. J. Physiol. Cell Physiol. 281: C1291-C1299.

Ito, M., Liu, Y., Yang, Z., Nguyen, J., Liang, F., Morris, R.J., and Cotsarelis, G. 2005. Stem cells in the hair follicle bulge contribute to wound repair but not to homeostasis of the epidermis. Nat. Med. 11: 1351-1354.

Iwanaga, K., Yang, Y., Raso, M.G., Ma, L., Hanna, A.E., Thilaganathan, N., Moghaddam, S., Evans, C.M., Li, H., Cai, W.W., et al. 2008. Pten inactivation accelerates oncogenic $K$ ras-initiated tumorigenesis in a mouse model of lung cancer. Cancer Res. 68: 1119-1127.

Jackson, E.L., Willis, N., Mercer, K., Bronson, R.T., Crowley, D., Montoya, R., Jacks, T., and Tuveson, D.A. 2001. Analysis of lung tumor initiation and progression using conditional expression of oncogenic K-ras. Genes Dev. 15: 3243-3248.

Ji, H., Ramsey, M.R., Hayes, D.N., Fan, C., McNamara, K., Kozlowski, P., Torrice, C., Wu, M.C., Shimamura, T., Perera, S.A., et al. 2007. LKB1 modulates lung cancer differentiation and metastasis. Nature 448: 807-810.

Johnson, L., Mercer, K., Greenbaum, D., Bronson, R.T., Crowley, D., Tuveson, D.A., and Jacks, T. 2001. Somatic activation of the $K$-ras oncogene causes early onset lung cancer in mice. Nature 410: 1111-1116.

Kanda, T., Sullivan, K.F., and Wahl, G.M. 1998. Histone-GFP fusion protein enables sensitive analysis of chromosome dynamics in living mammalian cells. Curr. Biol. 8: 377-385.
Kawamoto, M. and Fukuda, Y. 1990. Cell proliferation during the process of bleomycin-induced pulmonary fibrosis in rats. Acta Pathol. Jpn. 40: 227-238.

Kiel, M.J., He, S., Ashkenazi, R., Gentry, S.N., Teta, M., Kushner, J.A., Jackson, T.L., and Morrison, S.J. 2007. Haematopoietic stem cells do not asymmetrically segregate chromosomes or retain BrdU. Nature 449: 238-242.

Kim, C.F. 2007a. MAPK-ing out the pathways in lung stem cell regulation. Cell Stem Cell 1: 11-13.

Kim, C.F. 2007b. Paving the road for lung stem cell biology: Bronchioalveolar stem cells and other putative distal lung stem cells. Am. J. Physiol. Lung Cell. Mol. Physiol. 293: L1092-L1098.

Kim, C.F., Jackson, E.L., Woolfenden, A.E., Lawrence, S., Babar, I., Vogel, S., Crowley, D., Bronson, R.T., and Jacks, T. 2005. Identification of bronchioalveolar stem cells in normal lung and lung cancer. Cell 121: 823-835.

Kobayashi, S., Boggon, T.J., Dayaram, T., Janne, P.A., Kocher, O., Meyerson, M., Johnson, B.E., Eck, M.J., Tenen, D.G., and Halmos, B. 2005. EGFR mutation and resistance of nonsmall-cell lung cancer to gefitinib. N. Engl. J. Med. 352: 786-792.

Kosaka, T., Yatabe, Y., Endoh, H., Yoshida, K., Hida, T., Tsuboi, M., Tada, H., Kuwano, H., and Mitsudomi, T. 2006. Analysis of epidermal growth factor receptor gene mutation in patients with non-small cell lung cancer and acquired resistance to gefitinib. Clin. Cancer Res. 12: 5764-5769.

Kossatz, U. and Malek, N.P. 2007. p27: Tumor suppressor and oncogene...? Cell Res. 17: 832-833.

Lawson, D.A., Xin, L., Lukacs, R.U., Cheng, D., and Witte, O.N. 2007. Isolation and functional characterization of murine prostate stem cells. Proc. Natl. Acad. Sci. 104: 181-186.

Lee, K.J., Dietrich, P., and Jessell, T.M. 2000. Genetic ablation reveals that the roof plate is essential for dorsal interneuron specification. Nature 403: 734-740.

Li, C., Heidt, D.G., Dalerba, P., Burant, C.F., Zhang, L., Adsay, V., Wicha, M., Clarke, M.F., and Simeone, D.M. 2007. Identification of pancreatic cancer stem cells. Cancer Res. 67: 1030-1037.

Li, L. and Neaves, W.B. 2006. Normal stem cells and cancer stem cells: The niche matters. Cancer Res. 66: 4553-4557.

Liu, X., Driskell, R.R., and Engelhardt, J.F. 2006. Stem cells in the lung. Methods Enzymol. 419: 285-321.

Ma, L. and Wang, H.Y. 2007. Mitogen-activated protein kinase p38 regulates the Wnt/cyclic GMP/Ca ${ }^{2+}$ non-canonical pathway. J. Biol. Chem. 282: 28980-28990.

MacLaren, R.E., Pearson, R.A., MacNeil, A., Douglas, R.H., Salt, T.E., Akimoto, M., Swaroop, A., Sowden, J.C., and Ali, R.R. 2006. Retinal repair by transplantation of photoreceptor precursors. Nature 444: 203-207.

Mason, R.J., Williams, M.C., Moses, H.L., Mohla, S., and Berberich, M.A. 1997. Stem cells in lung development, disease, and therapy. Am. J. Respir. Cell Mol. Biol. 16: 355-363.

Mason-Richie, N.A., Mistry, M.J., Gettler, C.A., Elayyadi, A., and Wikenheiser-Brokamp, K.A. 2008. Retinoblastoma function is essential for establishing lung epithelial quiescence after injury. Cancer Res. 68: 4068-4076.

Massaro, G.D., Singh, G., Mason, R., Plopper, C.G., Malkinson, A.M., and Gail, D.B. 1994. Biology of the Clara cell. Am. J. Physiol. 266: L101-L106.

Mavilio, F., Pellegrini, G., Ferrari, S., Di Nunzio, F., Di Iorio, E., Recchia, A., Maruggi, G., Ferrari, G., Provasi, E., Bonini, C., et al. 2006. Correction of junctional epidermolysis bullosa by transplantation of genetically modified epidermal stem cells. Nat. Med. 12: 1397-1402.

McLemore, T.L., Liu, M.C., Blacker, P.C., Gregg, M., Alley, M.C., Abbott, B.J., Shoemaker, R.H., Bohlman, M.E., Litterst, C.C., Hubbard, W.C., et al. 1987. Novel intrapulmonary model for orthotopic propagation of human lung cancers in athymic nude mice. Cancer Res. 47: 5132-5140.

Meissner, K.K., Kirkham, D.L., and Doering, L.C. 2005. Transplants of neurosphere cell suspensions from aged mice are functional in the mouse model of Parkinson's. Brain Res. 1057: $105-112$. 
Metcalf, D. 2007. Concise review: Hematopoietic stem cells and tissue stem cells: Current concepts and unanswered questions. Stem Cells 25: 2390-2395.

Meuwissen, R. and Berns, A. 2005. Mouse models for human lung cancer. Genes Dev. 19: 643-664.

Mosher, J.T., Yeager, K.J., Kruger, G.M., Joseph, N.M., Hutchin, M.E., Dlugosz, A.A., and Morrison, S.J. 2007. Intrinsic differences among spatially distinct neural crest stem cells in terms of migratory properties, fate determination, and ability to colonize the enteric nervous system. Dev. Biol. 303: 1-15.

Nolen-Walston, R.D., Kim, C.F., Mazan, M.R., Ingenito, E.P., Gruntman, A.M., Tsai, L., Boston, R., Woolfenden, A.E., Jacks, T., and Hoffman, A.M. 2008. Cellular kinetics and modeling of bronchioalveolar stem cell response during lung regeneration. Am. J. Physiol. Lung Cell. Mol. Physiol. 294: L1158-L1165.

O’Brien, C.A., Pollett, A., Gallinger, S., and Dick, J.E. 2007. A human colon cancer cell capable of initiating tumour growth in immunodeficient mice. Nature 445: 106-110.

Onn, A., Isobe, T., Itasaka, S., Wu, W., O'Reilly, M.S., Ki Hong, W., Fidler, I.J., and Herbst, R.S. 2003. Development of an orthotopic model to study the biology and therapy of primary human lung cancer in nude mice. Clin. Cancer Res. 9: $5532-5539$.

Orford, K.W. and Scadden, D.T. 2008. Deconstructing stem cell self-renewal: Genetic insights into cell-cycle regulation. Nature Rev. 9: 115-128.

Osawa, M., Hanada, K., Hamada, H., and Nakauchi, H. 1996. Long-term lymphohematopoietic reconstitution by a single CD34-low/negative hematopoietic stem cell. Science 273: 242-245.

Palmiter, R.D., Behringer, R.R., Quaife, C.J., Maxwell, F., Maxwell, I.H., and Brinster, R.L. 1987. Cell lineage ablation in transgenic mice by cell-specific expression of a toxin gene. Cell 50: 435-443.

Pao, W., Miller, V.A., Politi, K.A., Riely, G.J., Somwar, R., Zakowski, M.F., Kris, M.G., and Varmus, H. 2005. Acquired resistance of lung adenocarcinomas to gefitinib or erlotinib is associated with a second mutation in the EGFR kinase domain. PLoS Med. 2: 73 .

Pei, X.H., Bai, F., Smith, M.D., and Xiong, Y. 2007. p18 ${ }^{\mathrm{Ink} 4 \mathrm{c}}$ collaborates with Men1 to constrain lung stem cell expansion and suppress non-small-cell lung cancers. Cancer Res. 67: 3162-3170

Perl, A.K., Wert, S.E., Nagy, A., Lobe, C.G., and Whitsett, J.A. 2002. Early restriction of peripheral and proximal cell lineages during formation of the lung. Proc. Natl. Acad. Sci. 99: 10482-10487.

Pietersen, A.M. and van Lohuizen, M. 2008. Stem cell regulation by polycomb repressors: Postponing commitment. Curr. Opin. Cell Biol. 20: 201-207.

Potten, C.S., Kellett, M., Roberts, S.A., Rew, D.A., and Wilson, G.D. 1992. Measurement of in vivo proliferation in human colorectal mucosa using bromodeoxyuridine. Gut 33: 71-78.

Powell, C.A., Spira, A., Derti, A., DeLisi, C., Liu, G., Borczuk, A., Busch, S., Sahasrabudhe, S., Chen, Y., Sugarbaker, D., et al. 2003. Gene expression in lung adenocarcinomas of smokers and nonsmokers. Am. J. Physiol. Cell. Mol. Biol. 29: 157162.

Rawlins, E.L. and Hogan, B.L. 2006. Epithelial stem cells of the lung: Privileged few or opportunities for many? Development 133: 2455-2465.

Rawlins, E.L., Ostrowski, L.E., Randell, S.H., and Hogan, B.L. 2007. Lung development and repair: Contribution of the ciliated lineage. Proc. Natl. Acad. Sci. 104: 410-417.

Reya, T., Morrison, S.J., Clarke, M.F., and Weissman, I.L. 2001 Stem cells, cancer, and cancer stem cells. Nature 414: 105 111

Reynolds, S.D., Giangreco, A., Power, J.H., and Stripp, B.R. 2000a. Neuroepithelial bodies of pulmonary airways serve as a reservoir of progenitor cells capable of epithelial regeneration. Am. J. Pathol. 156: 269-278.

Reynolds, S.D., Giangreco, A., Hong, K.U., McGrath, K.E., Ortiz, L.A., and Stripp, B.R. 2004. Airway injury in lung dis- ease pathophysiology: Selective depletion of airway stem and progenitor cell pools potentiates lung inflammation and alveolar dysfunction. Am. J. Physiol. Lung Cell. Mol. Physiol. 287: L1256-L1265.

Reynolds, S.D., Hong, K.U., Giangreco, A., Mango, G.W., Guron, C., Morimoto, Y., and Stripp, B.R. 2000b. Conditional Clara cell ablation reveals a self-renewing progenitor function of pulmonary neuroendocrine cells. Am. J. Physiol. Lung Cell. Mol. Physiol. 278: L1256-L1263.

Reynolds, S.D., Zemke, A.C., Giangreco, A., Brockway, B.L., Teisanu, R.M., Drake, J.A., Mariani, T., Di, P.Y., Taketo, M.M., and Stripp, B.R. 2008. Conditional stabilization of $\beta$ catenin expands the pool of lung stem cells. Stem Cells 26: 1337-1346.

Ricci-Vitiani, L., Lombardi, D.G., Pilozzi, E., Biffoni, M., Todaro, M., Peschle, C., and De Maria, R. 2007. Identification and expansion of human colon-cancer-initiating cells. Nature 445: $111-115$.

Richardson, G.D., Robson, C.N., Lang, S.H., Neal, D.E., Maitland, N.J., and Collins, A.T. 2004. CD133, a novel marker for human prostatic epithelial stem cells. J. Cell Sci. 117: 3539-3545.

Sangiorgi, E. and Capecchi, M.R. 2008. Bmil is expressed in vivo in intestinal stem cells. Nat. Genet. 40: 915-920.

Scadden, D.T. 2006. The stem-cell niche as an entity of action. Nature 441: 1075-1079.

Schatton, T., Murphy, G.F., Frank, N.Y., Yamaura, K., WaagaGasser, A.M., Gasser, M., Zhan, Q., Jordan, S., Duncan, L.M., Weishaupt, C., et al. 2008. Identification of cells initiating human melanomas. Nature 451: 345-349.

Shackleton, M., Vaillant, F., Simpson, K.J., Stingl, J., Smyth, G.K., Asselin-Labat, M.L., Wu, L., Lindeman, G.J., and Visvader, J.E. 2006. Generation of a functional mammary gland from a single stem cell. Nature 439: 84-88.

Sicinski, P., Zacharek, S., and Kim, C. 2007. Duality of p $27^{\text {Kip } 1}$ function in tumorigenesis. Genes Dev. 21: 1703-1706.

Singh, S.K., Hawkins, C., Clarke, I.D., Squire, J.A., Bayani, J., Hide, T., Henkelman, R.M., Cusimano, M.D., and Dirks, P.B. 2004. Identification of human brain tumour initiating cells. Nature 432: 396-401.

Stern, C.D. and Fraser, S.E. 2001. Tracing the lineage of tracing cell lineages. Nat. Cell Biol. 3: E216-E218.

Stripp, B.R. and Reynolds, S.D. 2008. Maintenance and repair of the bronchiolar epithelium. Proc. Am. Thorac. Soc. 5: 328-333.

Stripp, B.R., Maxson, K., Mera, R., and Singh, G. 1995. Plasticity of airway cell proliferation and gene expression after acute naphthalene injury. Am. J. Physiol. 269: L791-L799.

Tichelaar, J.W., Lu, W., and Whitsett, J.A. 2000. Conditional expression of fibroblast growth factor-7 in the developing and mature lung. J. Biol. Chem. 275: 11858-11864.

Till, J.E. and McCulloch, E.A. 1961. A direct measurement of the radiation sensitivity of normal mouse bone marrow cells. Radiat. Res. 14: 213-222.

Tumbar, T., Guasch, G., Greco, V., Blanpain, C., Lowry, W.E., Rendl, M., and Fuchs, E. 2004. Defining the epithelial stem cell niche in skin. Science 303: 359-363.

Tyagi, S., Srisuma, S., Bhattacharya, S., and Mariani, T.J. 2007. Developmental ontogeny of bronchio-alveolar stem cells. FASEB J. 21: 975-979.

van der Lugt, N.M., Domen, J., Linders, K., van Roon, M., Robanus-Maandag, E., te Riele, H., van der Valk, M., Deschamps, J., Sofroniew, M., van Lohuizen, M., et al. 1994. Posterior transformation, neurological abnormalities, and severe hematopoietic defects in mice with a targeted deletion of the bmi-1 proto-oncogene. Genes Dev. 8: 757-769.

Van der Schans, C.P. 2007. Bronchial mucus transport. Respir. Care 52: 1150-1158.

Van Winkle, L.S., Buckpitt, A.R., Nishio, S.J., Isaac, J.M., and Plopper, C.G. 1995. Cellular response in naphthalene-induced Clara cell injury and bronchiolar epithelial repair in mice. Am. J. Physiol. 269: L800-L818.

Ventura, J.J., Tenbaum, S., Perdiguero, E., Huth, M., Guerra, C., Barbacid, M., Pasparakis, M., and Nebreda, A.R. 2007. p38 $\alpha$ MAP kinase is essential in lung stem and progenitor cell pro- 
liferation and differentiation. Nat. Genet. 39: 750-758.

Visnjic, D., Kalajzic, Z., Rowe, D.W., Katavic, V., Lorenzo, J., and Aguila, H.L. 2004. Hematopoiesis is severely altered in mice with an induced osteoblast deficiency. Blood 103: 3258 3264 .

Whitsett, J.A. and Perl, A.K. 2006. Conditional control of gene expression in the respiratory epithelium: A cautionary note. Am. J. Respir. Cell Mol. Biol. 34: 519-520.

Wuenschell, C.W., Sunday, M.E., Singh, G., Minoo, P., Slavkin, H.C., and Warburton, D. 1996. Embryonic mouse lung epithelial progenitor cells co-express immunohistochemical markers of diverse mature cell lineages. J. Histochem. Cytochem. 44: 113-123.

Xin, L., Lawson, D.A., and Witte, O.N. 2005. The Sca-1 cell surface marker enriches for a prostate-regenerating cell subpopulation that can initiate prostate tumorigenesis. Proc. Natl. Acad. Sci. 102: 6942-6947.

Yanagi, S., Kishimoto, H., Kawahara, K., Sasaki, T., Sasaki, M.,
Nishio, M., Yajima, N., Hamada, K., Horie, Y., Kubo, H., et al. 2007. Pten controls lung morphogenesis, bronchioalveolar stem cells, and onset of lung adenocarcinomas in mice. $J$. Clin. Invest. 117: 2929-2940.

Yang, H., Lu, M.M., Zhang, L., Whitsett, J.A., and Morrisey, E.E. 2002. GATA6 regulates differentiation of distal lung epithelium. Development 129: 2233-2246.

Yang, Y., Iwanaga, K., Raso, M.G., Wislez, M., Hanna, A.E., Wieder, E.D., Molldrem, J.J., Wistuba, II, Powis, G., Demayo, F.J., Kim, C.F., and Kurie, J.M. 2008. Phosphatidylinositol 3-kinase mediates bronchioalveolar stem cell expansion in mouse models of oncogenic K-ras-induced lung cancer. PLOS ONE 3: e2220.

Zhang, Y., Goss, A.M., Cohen, E.D., Kadzik, R., Lepore, J.J., Muthukumaraswamy, K., Yang, J., DeMayo, F.J., Whitsett, J.A., Parmacek, M.S., and Morrisey, E.E. 2008. A Gata6-Wnt pathway required for epithelial stem cell development and airway regeneration. Nat. Genet. 40: 862-870. 


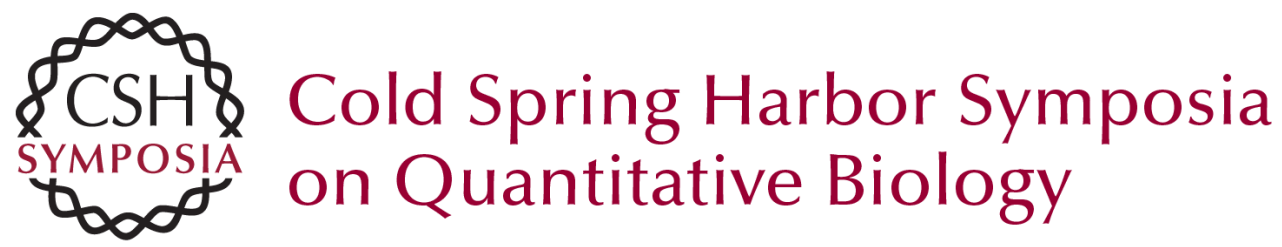

\section{Stem Cell Biology in the Lung and Lung Cancers: Using Pulmonary Context and Classic Approaches}

D.M. Raiser, S.J. Zacharek, R.R. Roach, et al.

Cold Spring Harb Symp Quant Biol 2008 73: 479-490 originally published online November 21, 2008 Access the most recent version at doi:10.1101/sqb.2008.73.036

References This article cites 107 articles, 36 of which can be accessed free at: http://symposium.cshlp.org/content/73/479.full.html\#ref-list-1

\section{License}

Email Alerting Service top right corner of the article or click here.

To subscribe to Cold Spring Harbor Symposia on Quantitative Biology go to: http://symposium.cshlp.org/subscriptions 